\title{
APPLICATION OF THE NEW NATO LOGISTICS SYSTEM
}

\author{
Miroslav PECINA \\ University of Defence, Brno, Department of Logistics, Czech Republic \\ miroslav.pecina@unob.cz \\ Jan HUSAK \\ Multinational Logistics Cooperation Centre, Czech Republic \\ husak_j@seznam.cz
}

\begin{abstract}
The article focuses on the current use of NATO's logistics information systems in NATO's defense planning and operational planning process in the logistics area. Information support is provided through NATO Logistics Functional Area Services (LOGFAS) Logistics Systems, which create the necessary information environment through individual software tools. In order to improve logistical information support, NATO is in parallel preparing for the modernization of the existing information environment and developing $L O G$ FS project that should replace existing information systems in the future, optimize information support, bring new functions and enable logistics operations coordination within NATO's integrated command and control network and between alliance and nations.
\end{abstract}

KEYWORDS: Logistics, support, logistics information systems, web orientation, development and implementation obstacles

\section{Introduction}

A corresponding network information environment and sufficient tools are a prerequisite for improving logistical efficiency in today's operating environment, characterized by frequent changes and the need for comprehensive multi-national security support in hostile environments that provide minimal local resources.

Logistics information systems have been used in the alliance for several decades, ranging from archaic simple from the late 1980s through the more comprehensive with more data collected, to the demand for a fully integrated logistics system currently being built.

The construction of the new system started the alliance in 2010 with a very optimistic assumption of implementation by 2016 (NATO CI Agency, 2014). Currently, work is underway on the creation of a new logistics information environment -Logistics Functional Services (LOG FS), to replace the existing LOGFAS. It is essential that LOG FS will fully support the functions necessary to command and control all parts of the logistics components, including the provision of logistics information to the Common Operational Picture (COP) and the implementation of Operational Logistics Chain Management (OLCM). By filling these functionalities, LOG FS will achieve full operational capability.

The LOG FS is expected to maximize the use of existing resources, tools and capabilities (such as LOGFAS functions), 
provide additional features including requirements that are not currently supported, improve overall integration, provide interoperable solutions using new technologies, and improve the environment the cost-effectiveness cycle, in particular eliminating duplication and centralizing common functions.

\section{Logistic Information System "Logistic Functional Area Services" (LOGFAS)}

The Logistic Functional Area Services (LOGFAS) logistics system was implemented at the end of the 1980 s as a temporary solution to enter a commercial solution via a supply chain. The system was designed to replace logistics formalized text reports that are specified in the Bi-SC 80-3 Volume V. The system has evolved throughout its existence both in content and functionally based on user requirements and the development of information technology (NATO HQ, 2001). The system uses logistics database (LOGBASE), which is at the heart of the NATO logistics information system LOGFAS. It contains information about the armed forces and assets used by NATO members, partner countries and other participating states, geographic information, infrastructure, health security, transport and shifts, inventory status, individual targets and other detailed data needed especially for planning and operational management of logistics support for the armed forces in multinational operations under NATO command. LOGBASE enables the management of these operational and logistic data and provides allied and national commanders with real-time information on capabilities and capabilities to meet the full range of missions. Based on the need to know principle, the staff of the competent headquarters can fully rely on a precise update to assess and evaluate the situation. LOGBASE is designed to be used in a wide range of logistics activities ranging from daily routine activities to defense planning.
To support the defense planning process in NATO, alliance developed the Allied Command Resource Optimization Software System (ACROSS) as part of the LOGFAS Information System. ACROSS is the NATO Subsystem for Decision Support in Ammunition Stockpile Planning. It consists of a database and four models for ammunition calculation. The LOGBASE shared database here serves as a storage of cost information on calculated ammunition. The calculation process of ammunition consumption is always realized using one of four models:

- ADMEM - Air Defense Munitions Expenditure Model;

- AGMEM - Air-to-Ground Munitions Expenditure Model;

- LEMEM - Land Forces Equipment and Munitions Expenditure Model;

- MARMEM - Maritime Munitions Expenditure Model.

Individual models use linear programming techniques to calculate the optimal ammunition composition in order to cause maximum damage to defined targets with the minimalised required cost levels for the acquisition of defined ammunition. ACROSS was used by the alliance for the number of defence planning cycles, in current time is used only on national level.

For the automated support of the logistics operational planning process, NATO uses the LOGFAS project, namely its following modules:

- GeoMan - Geographical Data Management Module;

- LDM - LOGFAS Data Management Module;

- SPM - Sustainment Planning Module;

- ADAMS - Allied Deployment and Movements System;

- CORSOM - Coalition Reception, Staging and Onward Movement.

The SDM (Supply Distribution Module) SDM is designed to verify and simulate planned logistic operations. After 
the launch of the multinational operation, an EVE (Effective Visual Execution) module is used for operational logistic control.

When the preparation of the new logistics information system LOG FS started, it was decided to stop the development of the existing LOGFAS system and about its transition to the faultremoval mode and the urgent operational requirements implementationrelated to the functionalities associated with the ongoing operations (NATO CI Agency, 2015). In this way, the functionalities necessary to ensure the operational needs of ISAF, RSM and the latest Host Nation Support Catalogue for the needs of the enhanced NATO Reaction Forces eNRF were implemented during the Year 2017 (NATO CI Agency, 2017a).

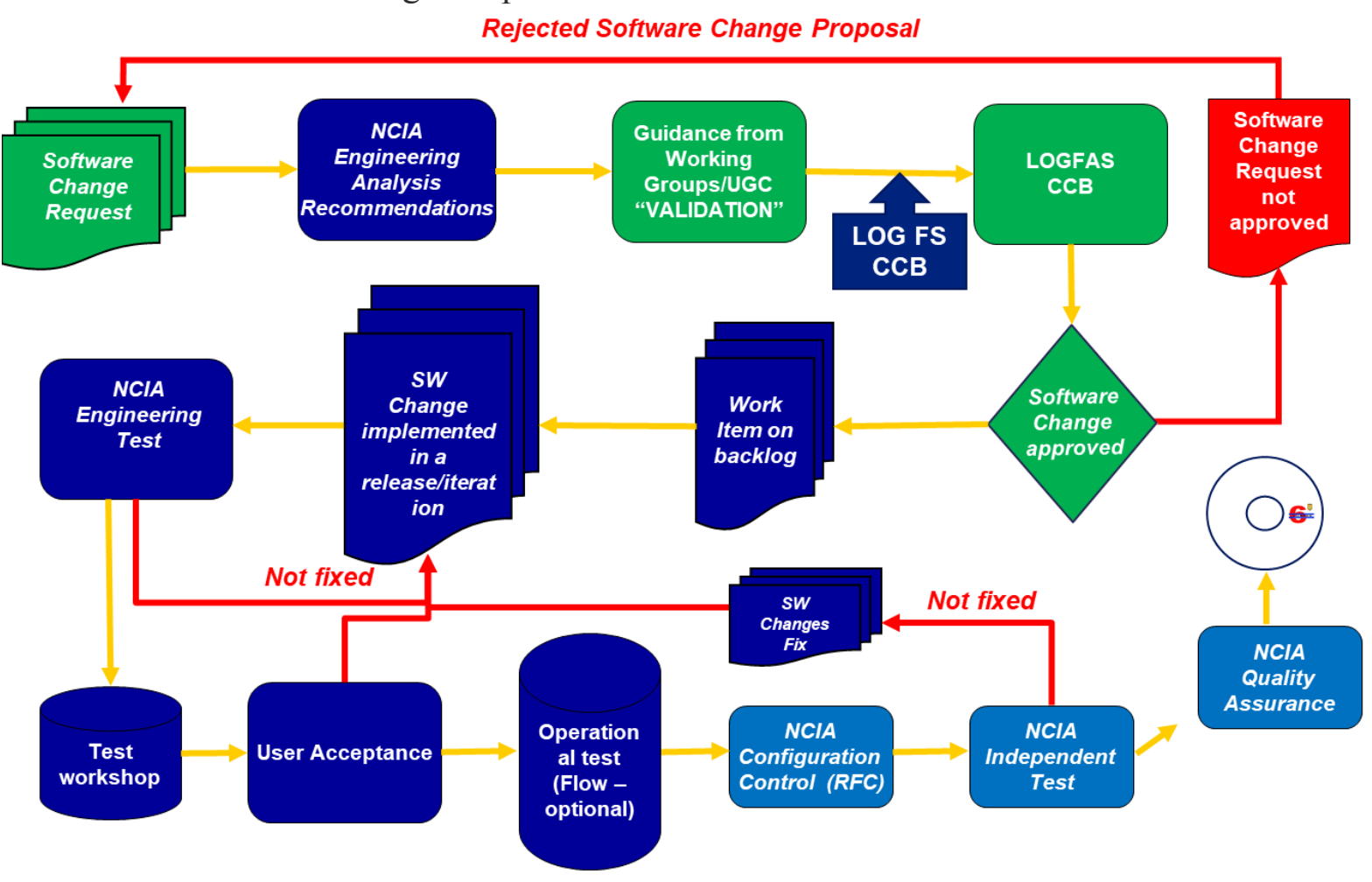

Figure no. 1: Acceptance and User Requirements Confirmation Process (source: NATO CI Agency, 2017b)

The troubleshooting and troubleshooting process is applied at least once a year based on verified user requirements. Each request is evaluated by the NATO Communications and Information Agency (NCIA) specialist and then handed over to the LOGREP WG to assess the importance. If critical, the patch is implemented almost immediately if it is not, fix is included in the subsequent system planned actualization (NATO CI Agency, 2017b).

\section{New Logistic System „Logistics Functional Services" (LOG FS)}

In 2010, NCIA accomplished an evaluation of the existing system (LOGFAS) in terms of further expansion and overall sustainability. The result of this study was the necessity to develop a new software tool due to the moral obsolescence of the LIS and the impossibility of recovering some critical parts of the software due to termination of their support by the distributors. The following requirement analysis has resulted in the 
transformation of existing LOGFAS functionality (Legacy Systems) and the addition of other required functionality to cover current requirements from areas not considered in the original SW solution.

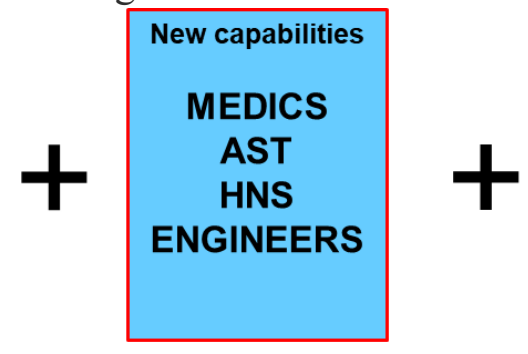

The new features included MEDICS, Asset Tracking (AST), Host Nation Support (HNS), and engineer support for logistics including infrastructure (Engineers).
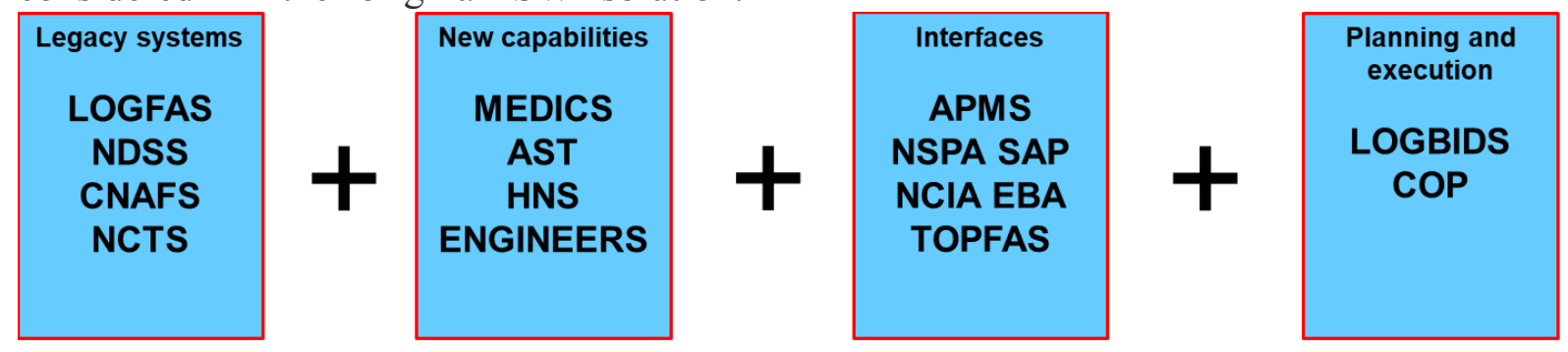

Figure no. 2: New Logistics Information System Structure (source: NATO CI Agency, 2015)

Other requirements for a new logistics information system were information systems and planning including automated connections with other alliance the logistic support for operations.

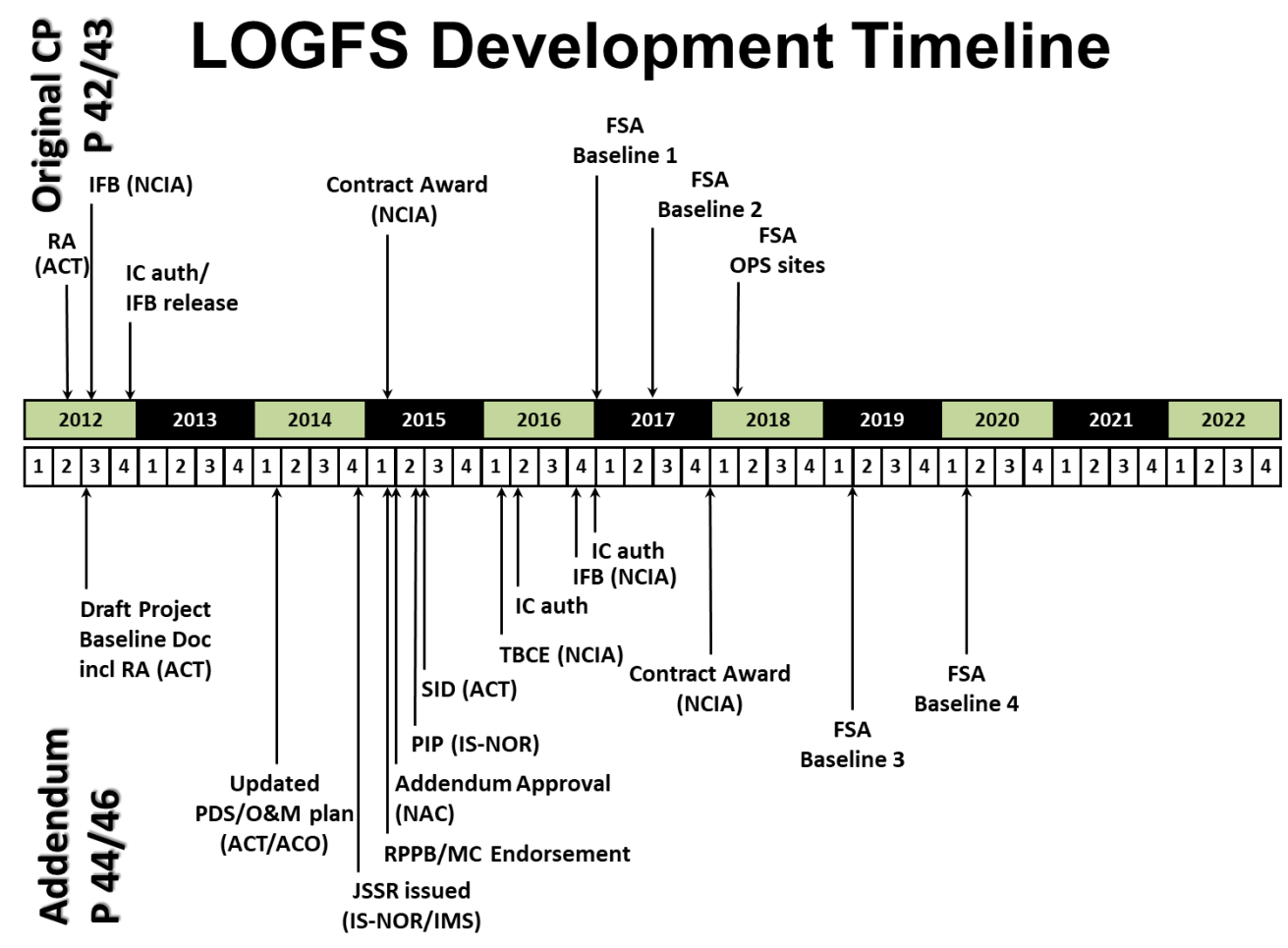

Figure no. 3: Initial Development and Implementation Timeline (source: NATO CI Agency, 2014)

All these requirements have been elaborated and implemented in detail as the Invitation for Bid - open competition on the professional level. The limiting factor of this tender documentation were overestimated user requirements as well as the processing time (first half of the Year 2012). In connection with the subsequent announcement of the competition, a timetable, which appeared realistic at that time, was consequently developed.

All requirements for a new logistics information system were divided into four projects - core 42 and 43 (consolidation and development phases) and complementary 44 and 46 (evolution stages 1 and 2). 


\section{Project 42 \\ Consolidation \\ Phase}

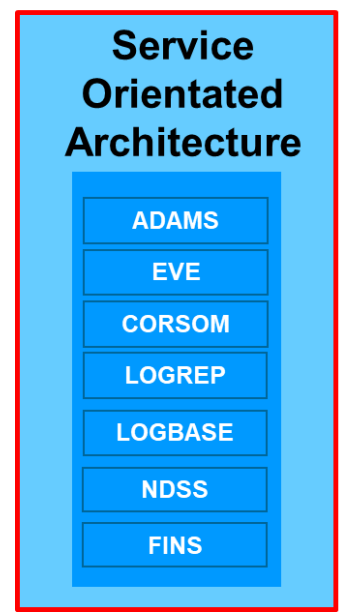

Project 43

Development

Phase

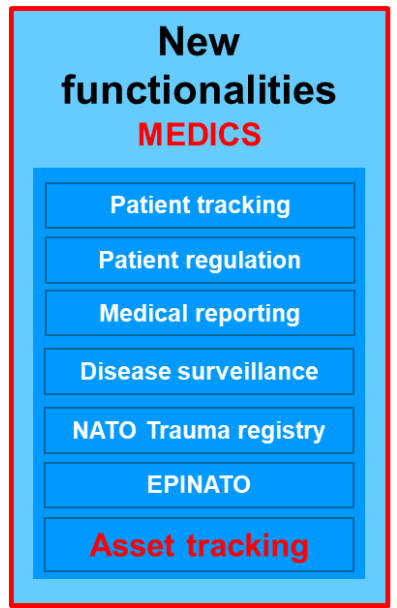

Figure no. 4: Projects 42/43 Content

(source: NATO CI Agency, 2014)

In a simplified way, it is possible to state that the content of project 42 is already existing logistic functionality, project 43 is oriented to the healthcare area by introducing automated processing and interconnection of information. Projects 44 and 46 further develop the system's capabilities in particular into the following areas:

- Strategic inventory planning,
- $\quad$ Scheduling of operational stocks, - Distribution Supply Model, - Interfacing with NSPA, - Common Operational Picture.

In order to reduce the volume of preparatory work, the contract was divided into two parts - Project 42/43 (Consolidation and development phases) and Project 44/46 (Evolution phases).

\section{Project 42 \\ Consolidation Phase}
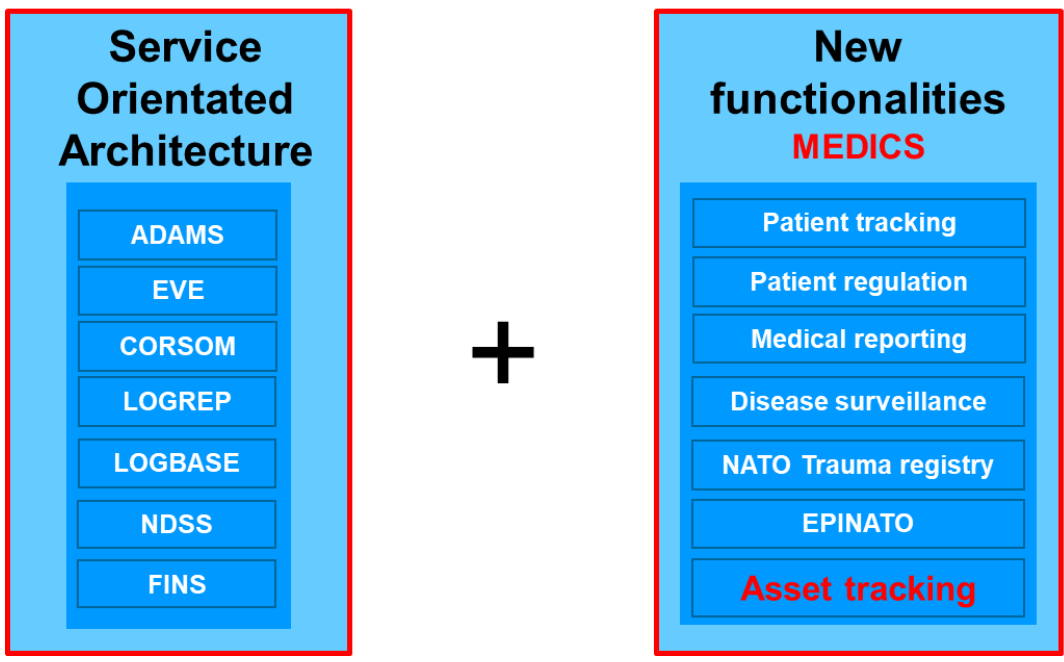

Figure no. 5: Projects 44/46 Content

(source: NATO CI Agency, 2014) 
Already at this stage there were shifts in the timetable - the contract officially started in April 2015, but the final contract with the consortium of winning companies was actually signed in autumn 2015. The whole program was modified from the outset by User Critical Requirements, and the launch of the second half was finally postponed after successful User acceptance tests of the projects $42 / 43$.

\section{Current Status}

The new logistics information system LOG FS is still in the testing stage, and more than 80 mistakes have been reported during the September 2017 control and acceptance tests. Follow on during the acceptance tests of version 2.1, 145 errors were indicated, 99 were removed, but from the remaining 46 are 34 major or critical. In addition, during the test, the number of errors does not decrease but, on the contrary, after the subsequent tests, it increased (NATO CI Agency, 2017). The overall situation does not look positively after several postponements. In the current situation, the public tender announcer commissioned an independent study to assess the scope of work and value of the existing SW solution. The next logical step is the termination of the contract with the current contractor, the new - objective specification of the LIS requirements, including all justified requests for changes initiated by the operational need.

This process will mean need for the extensive time window interconnected with the broad need to extend the functionality of the current Logistics Information System (LOGFAS) and to continue not only with routine maintenance, but also implement partial upgrades of individual subsystems in response to Critical User Requirements and operational needs.

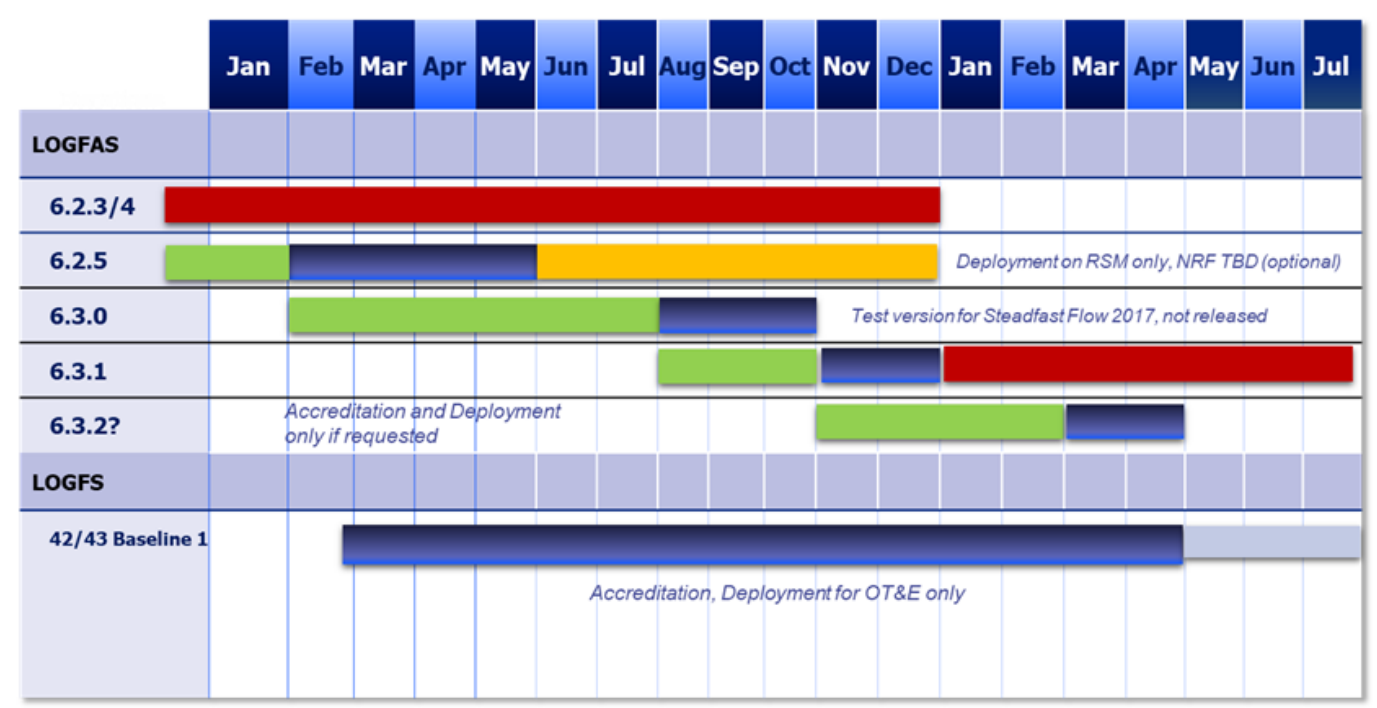

Figure no. 6: Current Development and Implementation Timeline (source: NATO CI Agency, 2017)

\section{Conclusion}

Following the ongoing problems with testing and implementation of the new logistics software (LOG FS), the alliance will need to reassess the support of the existing LIS (LOGFAS) and allocate resources not only to its maintenance but also to the necessary development and modernization associated with operational deployment and requirements. 
In connection with the possible withdrawal from the contract for the construction and implementation of the LOG FS and the subsequent settlement between the parties, it is possible to expect the increase of the initially allocated funds (about EUR 30 mil.) which, due to the necessity of approval by the budget committee of the alliance, will not be easy.
The next step will be to launch a new competition and the whole process will be repeated with the result of a two-to-threeyear shift in implementation of the LOG FS. This means that the current logistics information system LOGFAS will have to be operated at least until 2025, until full implementation of the second phase of the LOG FS project.

\section{REFERENCES}

NATO CI Agency. (2014). LOG FS Update. LOGREP WG SHAPE presentation. Mons, Belgium.

NATO CI Agency. (2015). LOG FS Update. LOGREP WG Presentation. Ramstein, Germany.

NATO CI Agency. (2017a). LOG FS Update. LOGREP WG Presentation. Paris, France.

NATO CI Agency. (2017b). LOGFAS Management. LOGREP WG Presentation. Paris, France.

NATO HQ. (2001). Bi-SC 80-3, volume V. Logistics Reporting. SHAPE, Belgium. 